\title{
Boussinesq modelling of tsunami and storm wave impact
}

DOI:

10.1680/eacm.13.00025

\section{Document Version}

Accepted author manuscript

Link to publication record in Manchester Research Explorer

\section{Citation for published version (APA):}

Mccabe, M., Stansby, P. K., Rogers, B. D., \& Cunningham, L. S. (2014). Boussinesq modelling of tsunami and storm wave impact. Institution of Civil Engineers. Proceedings. Engineering and Computational Mechanics, 167(3), 106-116. https://doi.org/10.1680/eacm.13.00025

\section{Published in:}

Institution of Civil Engineers. Proceedings. Engineering and Computational Mechanics

\section{Citing this paper}

Please note that where the full-text provided on Manchester Research Explorer is the Author Accepted Manuscript or Proof version this may differ from the final Published version. If citing, it is advised that you check and use the publisher's definitive version.

\section{General rights}

Copyright and moral rights for the publications made accessible in the Research Explorer are retained by the authors and/or other copyright owners and it is a condition of accessing publications that users recognise and abide by the legal requirements associated with these rights.

\section{Takedown policy}

If you believe that this document breaches copyright please refer to the University of Manchester's Takedown Procedures [http://man.ac.uk/04Y6Bo] or contact uml.scholarlycommunications@manchester.ac.uk providing relevant details, so we can investigate your claim.

\section{OPEN ACCESS}


Boussinesq modelling of tsunami and storm wave impact

Maurice McCabe, Peter K. Stansby, Benedict D. Rogers, Lee S. Cunningham

University of Manchester, School of Mechanical, Aerospace \& Civil Engineering

Author Accepted Manuscript

A paper submitted to Proceedings of the Institution of Civil Engineers - Engineering and Computational Mechanics

Paper Published 2014, DOI: http://dx.doi.org/10.1680/eacm.13.00025 


\section{Abstract (204 words)}

Many coastal protection structures in the UK have been designed for storm surges with appropriate return periods but their performance during tsunami-type waves is uncertain. $A$ shallow water and Boussinesq (referred to as SWAB) model is well suited to the investigation of both nearshore storm waves and tsunami waves. This paper makes use of the SWAB model to compare the effect on coastal structures of solitary waves and storm waves. Wave runup parameters for both types of wave are generated, and shown to be in good agreement with experimental data.

The equations behind the SWAB model were derived assuming a small bed slope, and are therefore not suitable for modelling waves interacting with vertical and near-vertical structures. However, the introduction of a reverse momentum term, to take account of a jet of water typical of a breaking wave impacting against a structure, allows wave overtopping volumes to be well predicted although it had a minor effect on the forces acting on the structure. Comparisons with experimental data, both with solitary waves and storm waves, are presented. Using this model, the difference between the impact, in terms of wave forces and wave overtopping, of tsunami waves and storm waves for a given structure is investigated.

\section{Keywords chosen from ICE Publishing list}

Coastal engineering; Sea defences; Computational mechanics.

\section{List of notation (examples below)}

$B \quad$ constant controlling linear dispersion in SWAB model

$C_{b}, C_{b t}$ breaking coefficients

$C_{f} \quad$ Friction coefficient $h_{i w}$ average water depth over a wavelength

d still-water depth

$d_{0} \quad$ wave paddle/input still-water depth

$F_{\text {wall }}$ reverse momentum term

$h(x, t)$ actual water depth

$h_{F} \quad$ vertical distance of application of reverse momentum term

$h_{i w} \quad$ average water depth over a wavelength

$H \quad$ wave height

$H_{i w} \quad$ height of an individual wave

$H_{m 0} \quad$ spectral significant wave height

$H_{0} \quad$ deepwater wave height (for storm waves), paddle/input wave height (for solitary waves)

$k_{\text {wall }}$ empirical constant for reverse momentum term

$L \quad$ wavelength

$L_{0} \quad$ deep-water wavelength

$L_{p} \quad$ wavelength based on $T_{p}$ 


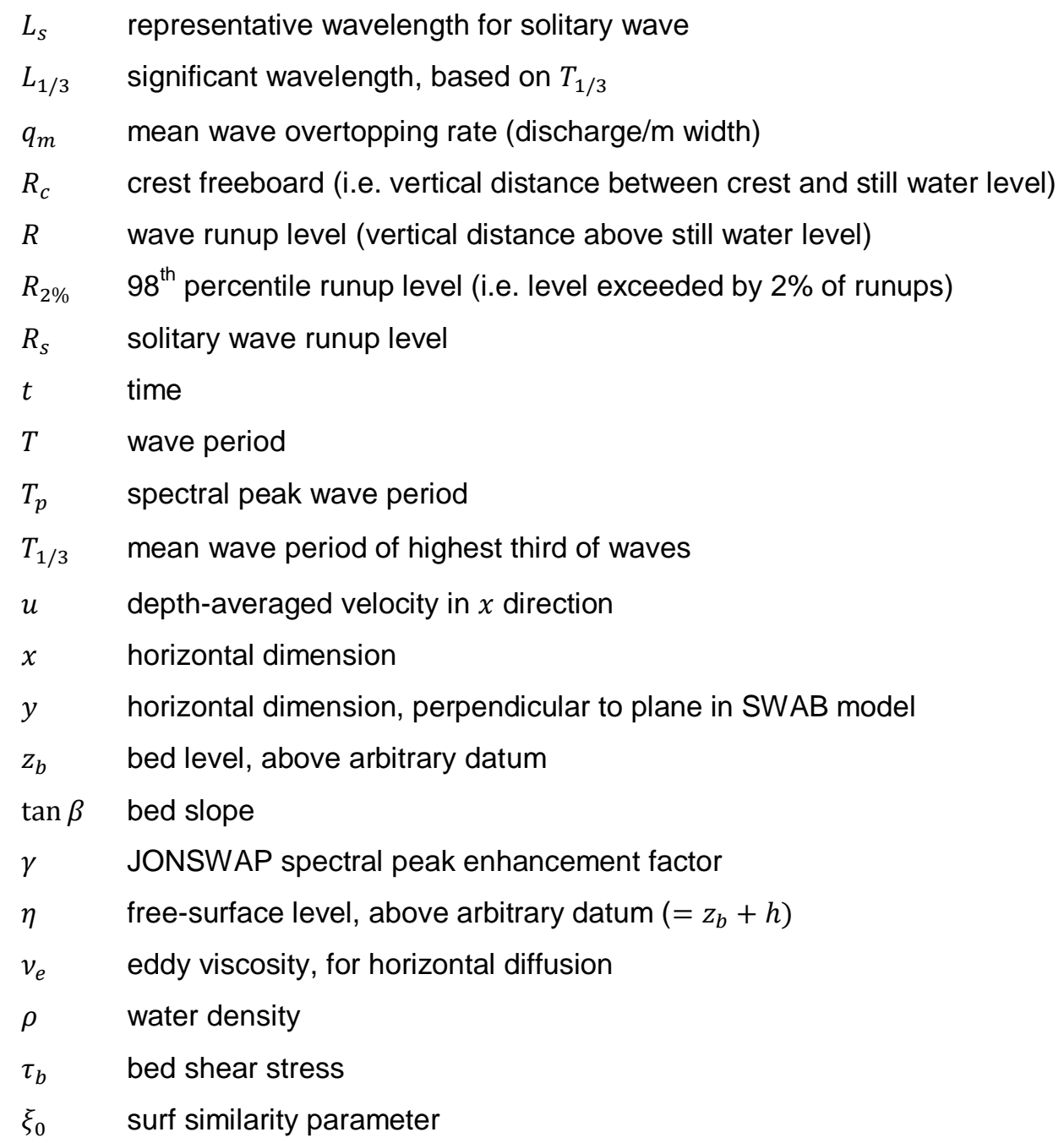




\section{Introduction}

In the UK, coastal structures are usually designed to protect against combinations of large waves and extreme high water levels, caused by storms. Tsunamis affecting the UK are very rare; confirmed examples include the Storegga tsunami of approximately 8000 years ago (Smith et al., 2004) and the tsunami resulting from the Lisbon earthquake of 1755 (Dawson et al., 2000). However, the widely publicised Indian Ocean tsunami of 2004 and the 2011 Japanese tsunami have led to a reassessment of the risk to the UK from such potentially catastrophic events. The present overall research project is investigating how climate change may cause crustal rebound as ice caps melt as well as causing the release of gas hydrates from marine sediments. This could lead to more frequent earthquakes and an increased submarine landslide risk (see http://arp.arctic.ac.uk/projects/landslide-tsunami/). The UK, and Scotland in particular, would be at risk from tsunamis from the Norwegian Sea, although the approach has a general international application.

Notwithstanding the different probabilities of occurrence, there are differences between tsunami and storm-related flood damage. Storm surge duration is of the order of several hours to days and they interact with tidal oscillations. Horsburgh and Wilson (2007) suggest that in the UK storm surge maxima do not occur at high tide. There will also be some correlation between the extreme water levels and large storm waves; a joint probability analysis is often carried out to provide combinations of waves and water levels for a given return period (e.g. Chini and Stansby, 2012).

It is not clear how tsunami damages compare with damages from storms. Being of the order of minutes in duration, a tsunami would not be expected to interact with tides in the same way; therefore one could occur during any part of the tidal cycle. A tsunami in the North Sea would take roughly one tidal cycle to propagate from north to south, so would be expected to coincide with high tide at some location. However, it is most unlikely that an extreme storm would coincide with a tsunami; therefore the associated storm and swell waves would be expected to be small.

It is common practice to use solitary waves to represent tsunamis, both in physical model tests and experimental simulations. Goring (1978) stated that waves with a net positive volume can be shown theoretically to eventually evolve into a series of solitary waves. Synolakis (1987) stated the relevance of solitary waves to the study of tsunamis. More recently, experiments carried out at the Tsunami Research Facility at Oregon State University (e.g. Linton et al. (2013)) use solitary waves to represent tsunamis. Despite this, Madsen et al. (2008), Segur (2007) and Arcas and Segur (2012) dispute the use of solitary waves to represent tsunamis, stating that both in the deep ocean and on the continental shelf, the length scale is insufficient for solitary waves to develop. Although their argument has a sound theoretical basis, the use of 
repeatable solitary waves for both physical and numerical investigations such as this is worthwhile and convenient.

The aim of this paper is to use a numerical model to show how storms and tsunamis compare. The shallow water and Boussinesq (SWAB) model used for this analysis was developed by Stansby (2003) and gave accurate results for solitary waves overtopping a trapezoidal sea wall (Stansby et al, 2008). It was further developed by McCabe et al. (2013) for storm wave overtopping. Boussinesq-type equations, where nonlinearity and dispersion are small but of similar magnitude, were originally derived as a model for solitary waves (Boussinesq, 1872; Peregrine, 1967) and have been used to model solitary wave runup by, for example, Borthwick et al (2006) and Dutych et al (2011) and to model tsunami propagation by, for example, Watts et al (2003). More modern Boussinesq-type derivations, such as those of Madsen and Sorensen (1992), allow for greater frequency dispersion and are therefore also valid for storm waves in transitional depths $\left(\frac{d}{L}<\frac{1}{2}\right)$, outside the surf zone. For breaking waves in shallow water, frequency dispersion is small. Here the Boussinesq terms in the equations are switched off and the depth-averaged nonlinear shallow water equations result. A similar method was adopted by Borthwick et al (2006) and Tonelli and Petti (2009).

The SWAB model used for this analysis is described in Section 2. In Sections 3 and 4, the SWAB model's performance in simulating storm waves and solitary waves respectively, will be discussed. These sections will compare SWAB model predictions against physical model data and empirical equations for wave overtopping volumes and forces against seawalls. In Section 5 the SWAB model will be applied to assess how the potential impact of the storm waves and tsunami waves (solitary waves) effect of a hypothetical tsunami would compare, through analysis of simulations of wave runup and forces on a vertical wall to the overtopping associated with a storm event. Section 6 will provide a discussion of the results.

\section{The SWAB Model}

The SWAB model is described in detail by McCabe et al. (2013). Many Boussinesq-type equations have been derived (as reviewed by Madsen and Schäffer, 1999), but those of Madsen and Sorensen (1992) have been widely tested, for example by Beji and Battjes (1994), and are used by SWAB, in one dimension. They consist of a continuity equation (1) and a momentum equation (2):

$$
\frac{\partial h}{\partial t}+\frac{\partial(h u)}{\partial x}=0
$$

1. 


$$
\begin{aligned}
\frac{\partial(h u)}{\partial t}+\frac{\partial\left(h u^{2}\right)}{\partial x}= & -g h \frac{\partial h}{\partial x}-g h \frac{\partial z_{b}}{\partial x}-\frac{\tau_{b}}{\rho} \\
+\left\{\left(B+\frac{1}{3}\right) d^{2}\left(\frac{\partial^{3}(h u)}{\partial x^{2} \partial t}\right)+B g d^{3} \frac{\partial^{3} \eta}{\partial x^{3}}\right. & \\
+ & \left.d \frac{\partial d}{\partial x}\left(\frac{1}{3} \frac{\partial^{2}(h u)}{\partial x \partial t}+2 B g d \frac{\partial^{2} \eta}{\partial x^{2}}\right)\right\}_{\text {non-breaking }} \\
& +\left\{\frac{\partial}{\partial x}\left(h\left(v+v_{e}\right) \frac{\partial u}{\partial x}\right)\right\}_{\text {breaking }}-F_{\text {wall }}
\end{aligned}
$$

2.

where $u$ is depth-averaged velocity, $h$ water depth, $d$ still-water depth, $z_{b}$ the bed level, $\tau_{b}$ bed shear stress, $\rho$ water density, $v$ kinematic viscosity of water, $v_{e}$ the wave breaking eddy viscosity and $F_{\text {wall }}$ is the reverse momentum term (see equation 6 ). The Boussinesq terms are the non-breaking part on the second and third lines of equation (2), where $B$ is a constant that controls the linear dispersion characteristics. The horizontal diffusion terms are the breaking part on the fourth line. Madsen and Sorensen (1992) found that $B=1 / 15$ gives the best linear dispersion. The model calculates numerical solutions for $h$ using a Crank-Nicolson semi-implicit method following Stansby (2003). This has the advantage of being more stable than fully explicit methods, without the damping effects of fully implicit methods. The bed shear stress is calculated using equation (3):

$\frac{\tau_{b}}{\rho}=\frac{C_{f} u|u|}{2}$

3.

where $C_{f}$ is a friction coefficient. McCabe (2011) found that reducing $C_{f}$ from 0.01 to 0.005 could increase the highest storm wave runup crests by $10 \%$, although it has little effect on wave heights in the surf zone.

The equations have no intrinsic wave breaking mechanism. Therefore, some criterion is required to determine where the wave breaking process occurs. At these locations, the nonbreaking terms of equation (2) are set to zero and the breaking (horizontal diffusion) term is switched on. McCabe et al. (2013) showed that a good breaking criterion for storm waves is:

$$
\frac{H_{i w}}{h_{i w}}>C_{b}
$$


where $H_{i w}$ is the height of an individual wave; and $h_{i w}$ is the mean water depth over that wavelength. $C_{b}$ is the breaking coefficient; McCabe et al. (2013) showed that $C_{b}=0.6$ works well for all tested regular and random wave conditions. Other Boussinesq type models have used criteria based on the free surface slope, either as a spatial gradient (e.g. Schaffer et al., 1993), or a rate of change of surface elevation with respect to time, which is equivalent to a surface slope (e.g. Kennedy et al., 2000). The following will be tested in this investigation.

$\frac{\partial \eta}{\partial t}>C_{b t} \sqrt{g h}$

5.

where $C_{b t}$ is a coefficient. It is likely that the best criterion or breaking coefficient value for solitary waves or tsunami-like waves may be different from that for storm waves.

The model equations were derived assuming small bed slopes and are therefore not suited to the modelling of steep revetments and vertical walls without modification. However McCabe et al. (2013) showed that inclusion of a reverse momentum term could greatly improve predictions of volumes for waves overtopping a revetment with a recurve wall. The reverse momentum is derived from the force imposed on a jet of water in a breaking wave impacting against a wall:

$F_{\text {wall }}=\frac{k_{\text {wall }} h_{F} u^{2}}{\Delta x}$

6.

where $h_{F}=\min (h, \Delta z) ; k_{\text {wall }}$ is an empirical constant; $\Delta x$ is the cell size and $\Delta z$ is the change in bed level from the given cell to the next cell (e.g. the wall height).

\section{SWAB Model - Storm Waves}

McCabe et al. (2013) compared SWAB model runs with laboratory and field datasets of wave overtopping volumes at a sea wall in Anchorsholme, near Blackpool, north-west England. The sea wall consists of a concrete stepped revetment (of 1 in 2 approximate slope), with a recurve wall set back $2.3 \mathrm{~m}$ from the top of the slope. A diagram of the sea wall profile (at the 1/15 scale used in the laboratory) is given by McCabe et al. (2013).

Best results for mean wave overtopping rates were achieved when the reverse momentum term was applied at the recurve wall only, with a value of $k_{\text {wall }}=1$. Different wall profiles may require different values for $k_{\text {wall }}$. A friction factor, $C_{f}=0.01$, was used for the SWAB model tests. Figure 1 (originally published in McCabe et al., 2013) shows SWAB calculated mean wave overtopping volumes for the entire set of physical model tests, in comparison with calculations using equation 5.8 of the Eurotop Manual (Pullen et al., 2007) and the Overtopping Neural Network 
tool (van Gent et al., 2007). Tested wave steepnesses $\left(\frac{2 \pi H_{m 0}}{g T_{p}^{2}}\right)$ were between 0.026 and 0.038 , and relative crest freeboards $\left(\frac{R_{c}}{H_{m 0}}\right)$ were between 0.73 and 2.24. In general, all three methods give similar results for mean overtopping rates; most predictions were within a factor of 2 of the experimental data, with the SWAB model tending to overestimate these volumes. Repeated SWAB model experiments using the same input wave spectrum with different random phases gave even large variation, with highest mean overtopping rates being approximately twice the lowest.

SWAB model runs were carried out to calculate maximum forces from random waves against a vertical breakwater. These forces were compared with those calculated using the formulae of Goda (2000, equations 4.2 to 4.8 ), with the results shown in Figure 2. Goda's basic method is valid for breaking and non-breaking waves propagating against vertical breakwaters. SWAB model runs consisted of 250 waves each; this is consistent with Goda's method, which uses a design wave based on the mean of the highest 1/250 of waves. For four selected wave conditions, SWAB simulations were repeated using different trains of random waves. Variation is large; in one case the largest recorded maximum was double the smallest maximum force. This reflects the random nature of the storm waves; the variation would reduce with longer model runs, but cannot be avoided entirely.

\section{SWAB Model - Solitary Waves}

Hsiao et al. (2008) investigated solitary wave propagation and runup, carrying out large-scale wave flume experiments with a 1 in 60 beach slope. 54 tests were carried out, with water depths at the paddle $\left(d_{0}\right)$ of $1.2 \mathrm{~m}$ or $2.2 \mathrm{~m}$, wave heights from $0.024 \mathrm{~m}$ to $0.406 \mathrm{~m}$ and wave height to depth ratios (nonlinearity) from 0.011 to 0.338 . A range of SWAB model runs was carried out, using a model domain with the same bed slope and wave input position as the physical model tests. A friction factor, $C_{f}=0.005$, was used for the SWAB model tests. Experiments were carried out investigating the effect of changing the wave breaking criterion on wave propagation and wave runup levels.

Figure 3 shows free-surface levels at various locations along the domain, in comparison with the physical model data. In each part of Figure 3, the respective wave is shown pre- and postbreaking; in Figure 3(a) the wave starts to break at $x=136 \mathrm{~m}$, and in Figure 3(b) at $x=160 \mathrm{~m}$. Wave propagation speeds and wave heights are accurately predicted for breaking and nonbreaking waves. However, the SWAB model appears to under-predict the wave height and the wave speed near the breaking point for Trial 43 (Figure 3(a)). The wave height under-prediction at $x=140 \mathrm{~m}$ could be due to the weak nonlinearity of the model equations being insufficient for simulation of the highly nonlinear waves that occur near where they start to break. In Figure 3(a) the shift to the nonlinear shallow water equations at the wave breaking location causes the 
celerity to become too small $\left(c=\sqrt{g h}\right.$, instead of $\left.c=\sqrt{g h}\left(1+\frac{H}{2 h}\right)\right)$; therefore the wave in the SWAB model arrives later than should be expected. In Figure $3(b)$ the increased breaking coefficient delays the onset of breaking, causing the wave to arrive at approximately the correct time. However this also allows a wave to become too large in the region where it should have started breaking (Figure 3(b), $x=156 \mathrm{~m}$ ).

Wave runup levels for all the Hsiao et al. (2008) tests, with SWAB simulations are shown in Figure 4. Three sets of SWAB simulations were carried out: two using the criterion of equation (4), with $C_{b}=0.6$ and $C_{b}=1.4$; and one using equation (5), with $C_{b t}=0.2$. It is apparent that the value of $C_{b}$ makes little difference to the results, with both $C_{b}=0.6$ and $C_{b}=1.4$ giving close matches to the experimental data. The criterion of equation (5) does not give a consistent match with the experiments, with runup levels being increasingly overestimated as the incident wave nonlinearity $\left(H_{0} / d_{0}\right)$ increases. Similar results have been observed when using the equation (5) criterion for storm waves (McCabe et al., 2013), with runup levels becoming overestimated for longer period waves.

Linton et al. (2013) presented experiments on the tsunami induced loading on wooden vertical walls, above the still water level. Although the experiments were carried out to simulate forces on buildings from tsunami waves, these loads can be equally representative of those likely to be encountered by coastal defence structures, as long as the structure is located above the still water level. Experiments were carried out in the Large Wave Flume at the Network for Earthquake Engineering (NEES) Tsunami Facility at Oregon State University; the flume set-up is shown in Figure 5. A vertical wooden structure, with load cells to measure horizontal forces, was placed on a horizontal berm above the still water level, approximately $0.08 \mathrm{~m}$ vertical distance and $8.2 \mathrm{~m}$ horizontal distance from the shoreline; Linton et al. (2013) provide a diagram of the experimental setup. Five different wave conditions were selected, for solitary waves; these are given in Table 1.

Figure 6 shows the progression of solitary wave L7 as it shoals and breaks in shallow water. Comparison of Figure $6(\mathrm{a})$ and Figure $6(\mathrm{~b})$ show that the breaking coefficient makes negligible difference to the wave progression. In fact, a small difference in free surface level was noticed at $x \approx 48 \mathrm{~m}$ (not shown in the figure) where the wave starts to break when $C_{b}=0.8$ but continues to shoal when $C_{b}=1.4$; however, by $x=50.4 \mathrm{~m}$ this difference is no longer visible.

Figure 7 shows time series of the forces imposed on the vertical wall. In all cases the SWAB model prediction of maximum force is within $20 \%$ of the experimental data. For wave L1, the difference is most apparent; the SWAB model records a force earlier than would be expected, suggesting that the incident bore is too large in height. For the other waves these differences are less apparent. It should be noted that the forces calculated by the SWAB model should be 
slightly higher than those recorded experimentally, due to the deflection of the wooden wall up to a maximum of approximately $6 \mathrm{~cm}$ for the $L 7$ case. In an alternative approach, Cunningham et al. (2014) have used the DualSPHysics SPH model with Abaqus to simulate these wave structure interactions.

Figure 8 shows that the contribution of the reverse momentum term (equation (6)) to the total force imposed is actually very small. As the bore makes contact with the vertical wall the depthaveraged velocity soon drops, and the force is largely due to hydrostatic load. By the time the maximum load is reached, the depth-averaged velocity is equal to zero.

Depending on the incident wave conditions, very large impulsive wave loads may be possible. These occur where a wave first breaks at the location of the breakwater or sea wall. Despite numerous experiments on impulsive loads (e.g. Kirkgoz, 1990, 1991, 1992; Cuomo et al., 2010, 2011) the physics of impulsive loading is not fully understood. It is clear however, that impulsive loads can be highly variable, with Kirkgoz (1991) showing that $90^{\text {th }}$ percentile loads are approximately double median loads for regular waves. The pressure on the wall is localised at a level close to the still water level. Impulse events are very short in duration; loading rise times are inversely proportional to the maximum load (i.e. the greatest impacts have the shortest duration). Impulses for the largest regular wave impacts recorded by Kirkgoz (1990) were less than $5 \mathrm{~ms}$ in duration. Two SWAB model runs were set up to attempt to reproduce the impulse forces; one with waves breaking near the wall $\left(C_{b}=0.6\right.$, using equation 4$)$, and the other without breaking waves ( $C_{b}=2.0$, using equation 4$)$. Figure 9 shows that neither case was able to simulate the impulsive behaviour recorded by Kirkgoz (1990). The SWAB model is unable to reproduce such impacts. The nature of these impacts cannot be approximated as depthaveraged, and are affected by factors such as plunging jets and air trapping. It was observed by Stansby and Feng (2005) that even the start of spilling breaking had a plunging form. It is unlikely that any shallow-water type model can accurately simulate the forces imposed. Numerous articles have solved the full Navier-Stokes equations to model the impact forces during wave breaking. One of the most promising methods is smoothed particle hydrodynamics (SPH). Colagrossi et al (2010) and Hughes and Graham (2010) for example, have used an SPH model to simulate such impacts.

\section{Comparison between storm waves and solitary waves}

Two important parameters will be considered here: wave runup on a sloping beach; and wave forces on a vertical wall. Comparisons between storm waves and solitary waves are complicated by the fact that some parameters associated with one type of wave (such as wavelength or $98^{\text {th }}$ percentile runup level) do not have a direct equivalent for the other type of wave; however, it is possible to calculate representative quantities. 
Wave runup levels are closely related to wave overtopping; hence any conditions that cause high runup levels will correspond to those that cause substantial overtopping. Based on extensive random wave tests, Mase (1989) calculated equations for a range of runup parameters of form:

$\frac{R}{H_{0}}=a_{r} \xi_{0}^{b_{r}}$

7.

where $R$ is the given runup parameter; $\xi_{0}=\frac{\tan \beta}{\sqrt{H_{0} / L_{0}}}$ is the surf similarity parameter, based on deepwater significant wave height and wavelength, with bed slope $\tan \beta$; and $a_{r}$ and $b_{r}$ are empirical constants. The most widely used parameter is the $98^{\text {th }}$ percentile runup level, $R_{2 \%}$, for which Mase (1989) calculated values of 1.86 and 0.71 for $a_{r}$ and $b_{r}$ respectively. Solitary wave runups have likewise been extensively researched. In general, following the analytical approach of Synolakis (1987), solitary wave runup levels are commonly presented in the form:

$\frac{R_{s}}{d_{0}}=a_{s}(\tan \beta)^{b_{s}}\left(\frac{H_{0}}{d_{0}}\right)^{c_{S}}$

8.

where $H_{0}$ and $d_{0}$ are the flat-bed (input) solitary wave height and still water depth respectively; and $a_{s}, b_{s}$ and $c_{s}$ are empirical parameters. Hsiao et al. (2008), based on solitary wave runup tests with slopes between 1 in 15 and 1 in 60 , gave values of $7.712,0.632$ and 0.618 for $a_{s}, b_{s}$ and $c_{s}$ respectively. (Note: Hsiao et al. (2008) used $\sin \left(\frac{H_{0}}{d_{0}}\right)$ in their relationship; for the values of $\left(\frac{H_{0}}{d_{0}}\right)$ that were considered, this is very close to the form of equation (8).)

A representative wavelength for a solitary wave can be calculated from its height and water depth:

$L_{s}=\frac{4 \pi}{\sqrt{3}} \sqrt{\frac{d_{0}^{3}}{H_{0}}}$

9.

Equation (9) allows a representative surf similarity parameter $\left(\frac{\tan \beta}{\sqrt{H_{0} / L_{s}}}\right)$ for solitary waves to be calculated. Then, equation (8) can be re-written in terms of $\frac{R_{S}}{H_{0}}$, giving the following relationship for solitary wave runup: 
$\frac{R_{s}}{H_{0}}=a_{s}^{\prime}\left(\frac{\tan \beta}{\sqrt{H_{0} / L_{s}}}\right)^{b_{s}}\left(\frac{H_{0}}{d_{0}}\right)^{c_{s}^{\prime}}$

10.

where $a_{s}^{\prime}=a_{s}\left(\frac{\sqrt{3}}{4 \pi}\right)^{\frac{b_{s}}{2}}$ and $c_{s}^{\prime}=c_{s}-1+\frac{3 b_{s}}{4}$. Using the values for $b_{s}$ and $c_{s}$ given by Hsiao et al. (2008), the exponent $c_{s}^{\prime}$ is relatively small (0.092); this means that the form of equation (7) is approximately valid for solitary waves.

Figure 10 shows values of $R_{2 \%}$, calculated using the SWAB model, for storm waves presented alongside runup levels for solitary waves, as a function of surf similarity parameter. All tests used the model domain from the Hsiao et al. (2008) tests. The storm wave tests used a JONSWAP spectrum $(\gamma=3.3)$, with approximately 200 waves per test. The surf similarity parameter used for the storm wave conditions in Figure 10 is based on the input wave conditions (i.e. $\xi_{\text {in }}=\frac{\tan \beta}{H_{m 0, i n} / L_{1 / 3, i n}}$ ), as opposed to deepwater conditions; this was to ensure that the parameter is as comparable as possible to that applied to the solitary waves. All conditions are given in Table 2.

It is clear that solitary waves give runup levels considerably higher than the extreme storm wave runup levels, for a given surf similarity parameter. The solitary wave results have been split depending on their value of $\frac{H_{0}}{d_{0}}$ : a strong dependency on $\left(\frac{H_{0}}{d_{0}}\right)^{c_{s}^{\prime}}$ would cause a distinct shift in runup levels between the separate series; this is not apparent, which suggests that $c_{s}^{\prime} \approx 0$. The storm wave data is more spread; that is the dependence of runup levels on surf similarity parameter is not as strong. This is partly due to the random nature of the waves: given only 200 waves per model run, considerable variation may be possible with a $98^{\text {th }}$ percentile runup level.

Storm wave runs for the tests of Linton et al. (2013) tests were set up using the SWAB model. Model runs of 200 random waves were run, with significant wave heights corresponding to the heights of the solitary waves of Table 1; a friction coefficient $C_{f}=0.005$ was used for both random and solitary wave tests. A wave steepness $\left(\frac{H_{m 0, \text { in }}}{L_{p, 0}}\right)$ of 0.015 was used for the random wave tests, which would be a very low value for waves in the North Sea, giving relatively high runup levels for a given wave height. Figure 11 shows the maximum force imposed on the wall from random waves for each of the five tests, alongside the experimental and numerical results. In all cases, the maximum force imposed on the wall from the storm waves is considerably less than that imposed by a solitary wave. For $H_{m 0}=0.1 \mathrm{~m}$, no storm waves reach the wall. $\mathrm{A}$ comparison between runs $L 5 a$, and $L 5 b$, with almost identical input conditions, shows that variation in maximum input forces for storm waves can be very large (the maximum force for $\mathrm{L} 5 \mathrm{~b}$ is $37 \%$ larger than that for $\mathrm{L} 5 \mathrm{a}$ ). 


\section{Discussion}

This paper has showed how the SWAB model can be used as a convenient tool for analysis of both storm waves and solitary waves. Simulations of wave overtopping rates, wave runup levels and forces on vertical structures all show good agreement with physical model datasets and widely used empirical formulae.

For solitary waves, very accurate predictions of wave runup levels on a 1 in 60 slope were obtained. Although the solitary waves were found to break before they reached the shore, and the height of the wave during the initial stage of breaking was affected by the breaking coefficient, this coefficient, $C_{b}$, had negligible influence on wave runup levels. As McCabe et al. (2013) found for storm waves, controlling the initiation of breaking with a limiting value of $\frac{H}{h}$ (equation 4) gives considerably better results for wave runup levels than a criterion based on $\frac{\partial \eta}{\partial t}$.

Forces are accurately predicted for non-breaking storm waves (in comparison with the formulae of Goda (2000)) as well as for breaking storm waves. For breaking solitary waves, the SWAB model also gives very good predictions of force imposed on a vertical wall. Photographs from the 2011 Japanese tsunami and the 2004 Indian Ocean tsunami show a wave that is already breaking by the time it reaches the shore. However, when breaking first occurs at the structure (impulsive loading), the SWAB model cannot simulate this phenomenon. It is unlikely that any shallow water model is able to simulate such impacts and a more sophisticated two-dimensional tool, such as the SPH model employed by Cunningham et al (2014), would be required.

The reverse momentum term (equation 6), that was shown by McCabe et al. (2013) to have a large influence on overtopping volumes for storm waves against a sea wall, does not appear to have a great effect on the force imposed on a wall because the loading is predominantly hydrostatic.

Comparison between runup levels from storm waves and solitary waves show that the solitary waves consistently give higher runup levels than the highest storm waves. At a typical wave steepness for storms in the North Sea, $(\approx 0.01)$, runup levels are approximately $50 \%$ higher for a solitary wave with a similar ratio of wave height to representative wavelength. It has also been shown that the force imposed by a solitary wave on a structure is likely to be greater than that from the highest storm waves of a similar wave height. It should be noted that this investigation used solitary waves as an idealisation for tsunamis where there is data for validation; future research will make use of more realistic tsunami waves.

\section{Conclusion}


In the UK, coastal structures have been designed to protect against waves and high water levels due to storms. Although tsunamis are very rare in this region, consideration of their impact may require different design guidance. It has been shown that the shallow water and Boussinesq (SWAB) model is a suitable tool for the analysis of both storm wave and solitary wave impact. It has been used here to make a comparison of the relative potential effects, in terms of wave runup and forces on vertical structures, from both types of wave. Further work would be required to analyse how consideration of tsunami impact may require changes to coastal structure design.

\section{Acknowledgements}

This work was supported by the Natural Environment Research Council grant number $\mathrm{NE} / \mathrm{K000160/1}$, which is part of the project: "Will climate change in the Arctic increase the landslide-tsunami risk to the UK?", involving teams from University of Aberdeen, British Geological Survey, University of Cambridge, University of Dundee, Imperial College London, University of Manchester, National Oceanography Centre, University of Southampton and University of Ulster. We acknowledge the helpful comments from the reviewers.

\section{References}

Arcas D and Segur H (2012) Seismically generated tsunamis. Philosophical Transactions of the Royal Society A: Mathematical, Physical and Engineering Sciences 370(1964): 1505-1542.

Beji S and Battjes JA (1994) Numerical simulation of nonlinear wave propagation over a bar. Coastal Engineering 23(1): 1-16.

Borthwick AGL, Ford M, Weston BP, Taylor PH, and Stansby PK (2006) Solitary wave transformation, breaking and run-up at a beach. Proceedings of the Institution of Civil Engineers - Maritime Engineering 159(3): 97-105.

Boussinesq MJ (1872) Théorie des ondes et des remous qui se propagent le long d'un canal rectangulaire horizontal, en communiquant au liquide contenu dans ce canal des vitesses sensiblement pareilles de la surface au fond. Journal de Mathématiques Pures et Appliquées, Deuxième Série 17: 55-108.

Chini N and Stansby PK (2012) Extreme values of coastal wave overtopping accounting for climate change and sea level rise. Coastal Engineering 65: 27-37.

Colagrossi A, Lugni C and Brocchini M (2010) A study of violent sloshing wave impacts using an improved SPH method. Journal of Hydraulic Research 48(S1): 94-104.

Cunningham LS, Rogers BD and Pringgana G (2014) Tsunami Wave and Structure Interaction: An Investigation with SPH, submitted to ICE Proceedings for Engineering and Computational Mechanics, December 2013.

Cuomo G, Allsop W, Bruce T and Pearson J (2010) Breaking wave loads at vertical seawalls and breakwaters. Coastal Engineering 57: 424-439. 
Cuomo G, Piscopia R and Allsop W (2011) Evaluation of wave impact loads on caisson breakwaters based on joint probability of impact maxima and rise times. Coastal Engineering 58: 9-27.

Dawson AG, Musson RMW, Foster IDL and Brunsden D (2000) Abnormal historic sea-surface fluctuations, SW England. Marine Geology 170(1): 59-68.

Dutykh D, Katsaounis T, and Mitsotakis D. (2011) Finite volume schemes for dispersive wave propagation and runup. Journal of Computational Physics 230(8): 3035-3061.

Goda Y (2000) Random Seas and Design of Maritime Structures, $2^{\text {nd }}$ edition. World Scientific Publishing, Singapore.

Goring DG (1978) Tsunamis--the propagation of long waves onto a shelf. PhD Thesis.

Horsburgh KJ and Wilson C (2007) Tide-surge interaction and its role in the distribution of surge residuals in the North Sea. Journal of Geophysical Research 112: C08003, doi:10.1029/2006JC004033.

Hsiao SC, Hsu TW, Lin TC and Chang YH (2008) On the evolution and run-up of breaking solitary waves on a mild sloping beach. Coastal Engineering 55: 975-988.

Hughes JP and Graham DI (2010) Comparison of incompressible and weakly-compressible SPH models for free-surface water flows. Journal of Hydraulic Research 48(S1): 105-117.

Kennedy AB, Chen Q, Kirby JT and Dalrymple RA (2000) Boussinesq modeling of wave transformation, breaking, and runup. I: 1D. Journal of Waterway, Port, Coastal, and Ocean Engineering 126(1): 39-47.

Kirkgöz MS (1990) An experimental investigation of a vertical wall response to breaking wave impact. Ocean Engineering 17(4): 379-391.

Kirkgöz MS (1991) Impact pressure of breaking waves on vertical and sloping walls. Ocean Engineering 18(1): 45-59

Kirkgöz MS (1992) Influence of water depth on the breaking wave impact on vertical and sloping walls. Coastal engineering 18: 297-314.

Linton D, Gupta R, Cox D et al (2012) Evaluation of Tsunami Loads on Wood Frame Walls at Full Scale. Journal of Structural Engineering 139(8): 1318-1325.

Madsen PA, Fuhrman DR and Schäffer HA (2008) On the solitary wave paradigm for tsunamis. Journal of Geophysical Research 113: C12012, doi:10.1029/2008JC004932.

Madsen PA and Sorensen OR (1992) A new form of the Boussinesq equations with improved linear dispersion characteristics. Part 2. A slowly varying bathymetry. Coastal Engineering 18: 183-204.

Mase H (1989) Random wave runup height on gentle slope. Journal of Waterway, Port, Coastal, and Ocean Engineering 115(5): 649-661.

McCabe MV (2011) Modelling Nearshore Waves, Runup and Overtopping. PhD Thesis, University of Manchester, UK.

McCabe MV, Stansby PK and Apsley DD (2013) Random wave runup and overtopping a steep sea wall: Shallow-water and Boussinesq modelling with generalised breaking and wall 
impact algorithms validated against laboratory and field measurements. Coastal Engineering 74: 33-49.

Peregrine DH (1967) Long waves on a beach. Journal of Fluid Mechanics 27: 815-827.

Pullen T, Allsop NWH, Bruce T et al. (2007) EurOtop. Wave Overtopping of Sea Defences and Related Structures: Assessment Manual. See http://www.overtoppingmanual.com/eurotop.pdf (accessed 04/03/2014).

Schäffer HA, Madsen PA and Deigaard R (1993) A Boussinesq model for waves breaking in shallow water. Coastal Engineering 20: 185-202.

Segur H (2007) Waves in shallow water, with emphasis on the tsunami of 2004. In Tsunami and nonlinear waves (Kundu A (ed)). Springer Berlin Heidelberg, pp. 3-29.

Smith D, Shi S, Cullingford RA et al. (2004) The Holocene Storegga Slide tsunami in the United Kingdom. Quaternary Science Reviews 23: 2291-2321.

Synolakis CE (1987) The runup of solitary waves. Journal of. Fluid Mechanics 185: 523-545.

Stansby PK (2003) Solitary wave run up and overtopping by a semi-implicit finite-volume shallow-water Boussinesq model. Journal of Hydraulic Research 41(6): 639-647.

Stansby PK, Xu R, Rogers BD et al (2008) Modelling tsunami overtopping of a sea defence by shallow-water Boussinesq, VOF and SPH methods. In FLOODrisk 2008: The European Conference on Flood Risk Management. Oxford, UK, pp. 255-261.

Tonelli $\mathrm{M}$ and Petti M (2009) Hybrid finite volume-finite difference scheme for 2DH improved Boussinesq equations. Coastal Engineering 56(5): 609-620.

van Gent MR, van den Boogaard HF, Pozueta B and Medina JR (2007) Neural network modelling of wave overtopping at coastal structures. Coastal Engineering 54: 586-593.

Watts P, Grilli ST, Kirby JT, Fryer GJ and Tappin DR (1999) Landslide tsunami case studies using a Boussinesq model and a fully nonlinear tsunami generation model. Natural Hazards And Earth System Science 3(5): 391-402. 


\section{Tables}

Table 1. Selected wave conditions from Linton et al. (2013) experiments.

\begin{tabular}{llll}
\hline Run Name & \multicolumn{1}{l}{ Input wave } & height, Input water depth, & $H_{0} / d_{0}$ \\
\hline L1 & $H_{0}(\mathrm{~m})$ & $d_{0}(\mathrm{~m})$ & 0.044 \\
L3 & 0.1 & 2.276 & 0.131 \\
L5a & 0.3 & 2.283 & 0.220 \\
L5b & 0.5 & 2.274 & 0.219 \\
L7 & 0.5 & 2.285 & 0.307 \\
\hline
\end{tabular}

Table 2. Input storm wave conditions for comparison with solitary wave runup levels.

\begin{tabular}{|c|c|c|c|c|}
\hline \multirow{2}{*}{$\begin{array}{l}\text { Input } \\
\text { height, } \\
\text { (m) }\end{array}$} & \multirow{2}{*}{$\begin{array}{l}\text { wave Input peak } \\
H_{m 0, i n} \text { wave period, } T_{p} \\
\text { (s) }\end{array}$} & & \multirow{2}{*}{$\begin{array}{l}\text { Significant } \\
\text { wavelength at } \\
\text { input, } L_{1 / 3, \text { in }} \\
\text { (s) }\end{array}$} & \multirow{2}{*}{$\frac{\tan \beta}{H_{m 0, \text { in }} / L_{1 / 3, \text { in }}}$} \\
\hline & & $\begin{array}{l}\text { input, } \quad T_{1 / 3, \text { in }} \\
\text { (s) }\end{array}$ & & \\
\hline$\overline{0.01}$ & 2.53 & 2.43 & 8.50 & 0.486 \\
\hline 0.02 & 3.58 & 3.43 & 13.92 & 0.440 \\
\hline 0.03 & 4.38 & 4.10 & 17.35 & 0.401 \\
\hline 0.04 & 5.06 & 4.79 & 20.83 & 0.380 \\
\hline 0.05 & 5.66 & 5.32 & 23.42 & 0.361 \\
\hline 0.06 & 6.20 & 5.78 & 25.67 & 0.345 \\
\hline 0.07 & 6.70 & 6.42 & 28.73 & 0.338 \\
\hline 0.08 & 7.16 & 6.80 & 30.58 & 0.326 \\
\hline 0.09 & 7.59 & 7.33 & 33.11 & 0.320 \\
\hline 0.1 & 8.00 & 7.36 & 33.27 & 0.304 \\
\hline 0.11 & 8.39 & 7.79 & 35.31 & 0.299 \\
\hline 0.12 & 8.77 & 8.11 & 36.85 & 0.292 \\
\hline 0.13 & 9.12 & 8.51 & 38.73 & 0.288 \\
\hline 0.14 & 9.47 & 9.02 & 41.14 & 0.286 \\
\hline 0.15 & 9.80 & 9.29 & 42.41 & 0.280 \\
\hline 0.16 & 10.12 & 9.69 & 44.31 & 0.277 \\
\hline 0.17 & 10.43 & 9.81 & 44.87 & 0.271 \\
\hline 0.18 & 10.74 & 10.17 & 46.59 & 0.268 \\
\hline 0.19 & 11.03 & 10.23 & 46.87 & 0.262 \\
\hline 0.2 & 11.32 & 10.67 & 48.92 & 0.261 \\
\hline 0.1 & 2.53 & 2.37 & 8.20 & 0.151 \\
\hline 0.15 & 3.10 & 2.94 & 11.32 & 0.145 \\
\hline 0.2 & 3.58 & 3.47 & 14.12 & 0.140 \\
\hline 0.25 & 4.00 & 3.78 & 15.75 & 0.132 \\
\hline 0.3 & 4.38 & 4.11 & 17.42 & 0.127 \\
\hline 0.35 & 4.73 & 4.56 & 19.67 & 0.125 \\
\hline 0.4 & 5.06 & 4.77 & 20.72 & 0.120 \\
\hline 0.45 & 5.37 & 5.11 & 22.40 & 0.118 \\
\hline
\end{tabular}




\begin{tabular}{|c|c|c|c|c|}
\hline 0.5 & 5.66 & 5.33 & 23.49 & 0.114 \\
\hline 0.55 & 5.94 & 5.58 & 24.69 & 0.112 \\
\hline 0.6 & 6.20 & 5.71 & 25.32 & 0.108 \\
\hline 0.65 & 6.45 & 5.69 & 25.22 & 0.104 \\
\hline 0.7 & 6.70 & 6.11 & 27.24 & 0.104 \\
\hline 0.75 & 6.93 & 5.85 & 26.01 & 0.098 \\
\hline 0.8 & 7.16 & 6.12 & 27.31 & 0.097 \\
\hline 0.85 & 7.38 & 6.02 & 26.83 & 0.094 \\
\hline 0.9 & 7.59 & 6.18 & 27.58 & 0.092 \\
\hline 0.95 & 7.80 & 6.43 & 28.82 & 0.092 \\
\hline 1 & 8.00 & 6.65 & 29.85 & 0.091 \\
\hline 1.05 & 8.20 & 7.13 & 32.17 & 0.092 \\
\hline 0.35 & 2.12 & 2.03 & 6.28 & 0.071 \\
\hline 0.4 & 2.26 & 2.17 & 7.06 & 0.070 \\
\hline 0.45 & 2.40 & 2.30 & 7.77 & 0.069 \\
\hline 0.5 & 2.53 & 2.45 & 8.62 & 0.069 \\
\hline 0.55 & 2.65 & 2.56 & 9.28 & 0.068 \\
\hline 0.6 & 2.77 & 2.67 & 9.87 & 0.068 \\
\hline 0.65 & 2.89 & 2.83 & 10.72 & 0.068 \\
\hline 0.7 & 2.99 & 2.91 & 11.18 & 0.067 \\
\hline 0.75 & 3.10 & 2.95 & 11.36 & 0.065 \\
\hline 0.8 & 3.20 & 3.06 & 11.98 & 0.065 \\
\hline 0.85 & 3.30 & 3.28 & 13.13 & 0.066 \\
\hline 0.9 & 3.40 & 3.31 & 13.29 & 0.064 \\
\hline 0.95 & 3.49 & 3.41 & 13.81 & 0.064 \\
\hline 1 & 3.58 & 3.48 & 14.21 & 0.063 \\
\hline 1.05 & 3.67 & 3.63 & 14.97 & 0.063 \\
\hline 1.1 & 3.75 & 3.61 & 14.85 & 0.061 \\
\hline 1.15 & 3.84 & 3.75 & 15.59 & 0.061 \\
\hline 1.2 & 3.92 & 3.92 & 16.47 & 0.062 \\
\hline 1.25 & 4.00 & 3.85 & 16.10 & 0.060 \\
\hline 1.3 & 4.08 & 3.94 & 16.55 & 0.060 \\
\hline
\end{tabular}




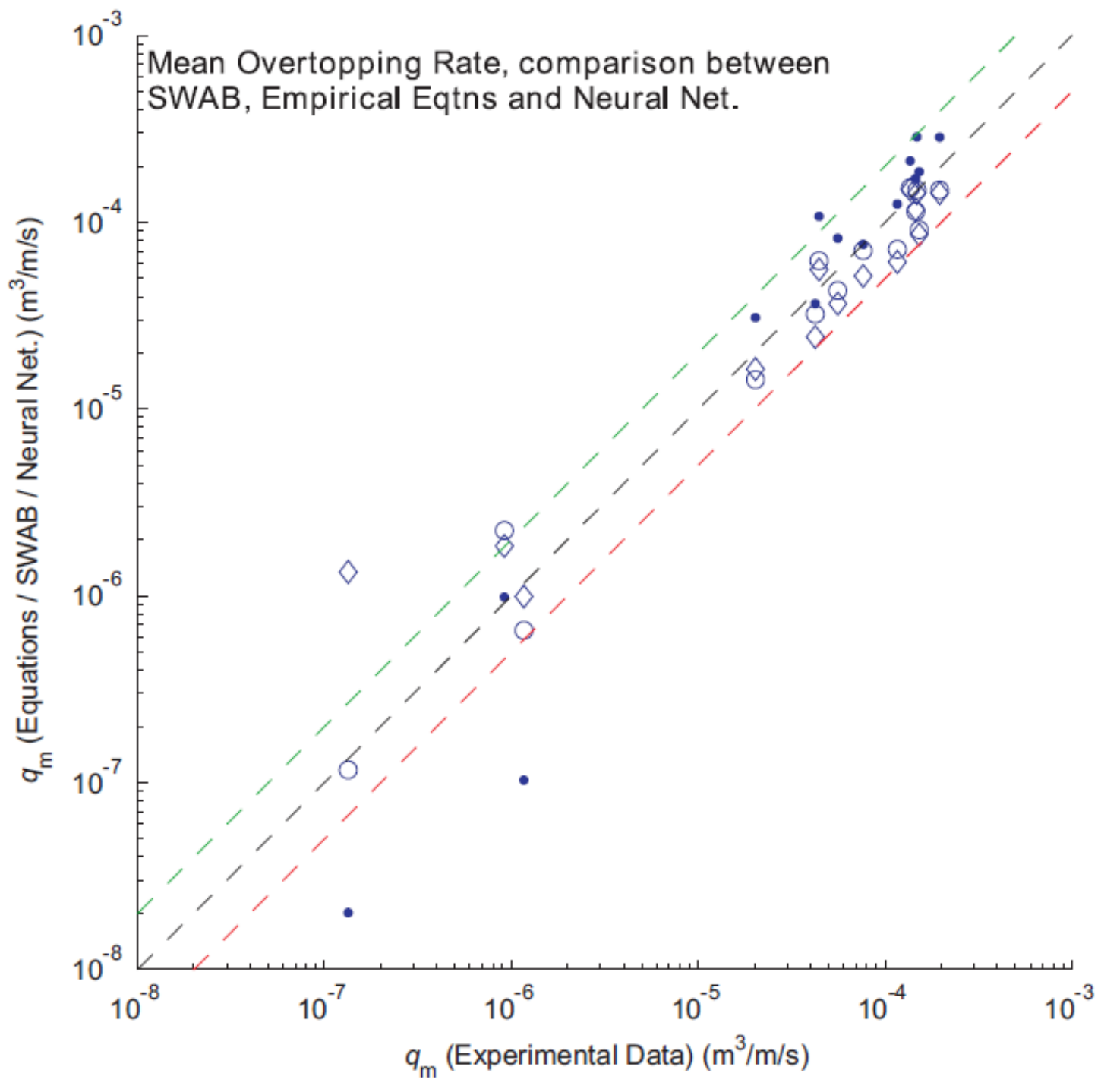

Figure 1. Mean overtopping volumes: SWAB model (•), Eurotop equations (o) and Overtopping Neural Network $(\diamond)$ compared with data from physical model tests. Figure originally appeared in McCabe et al. (2013). 


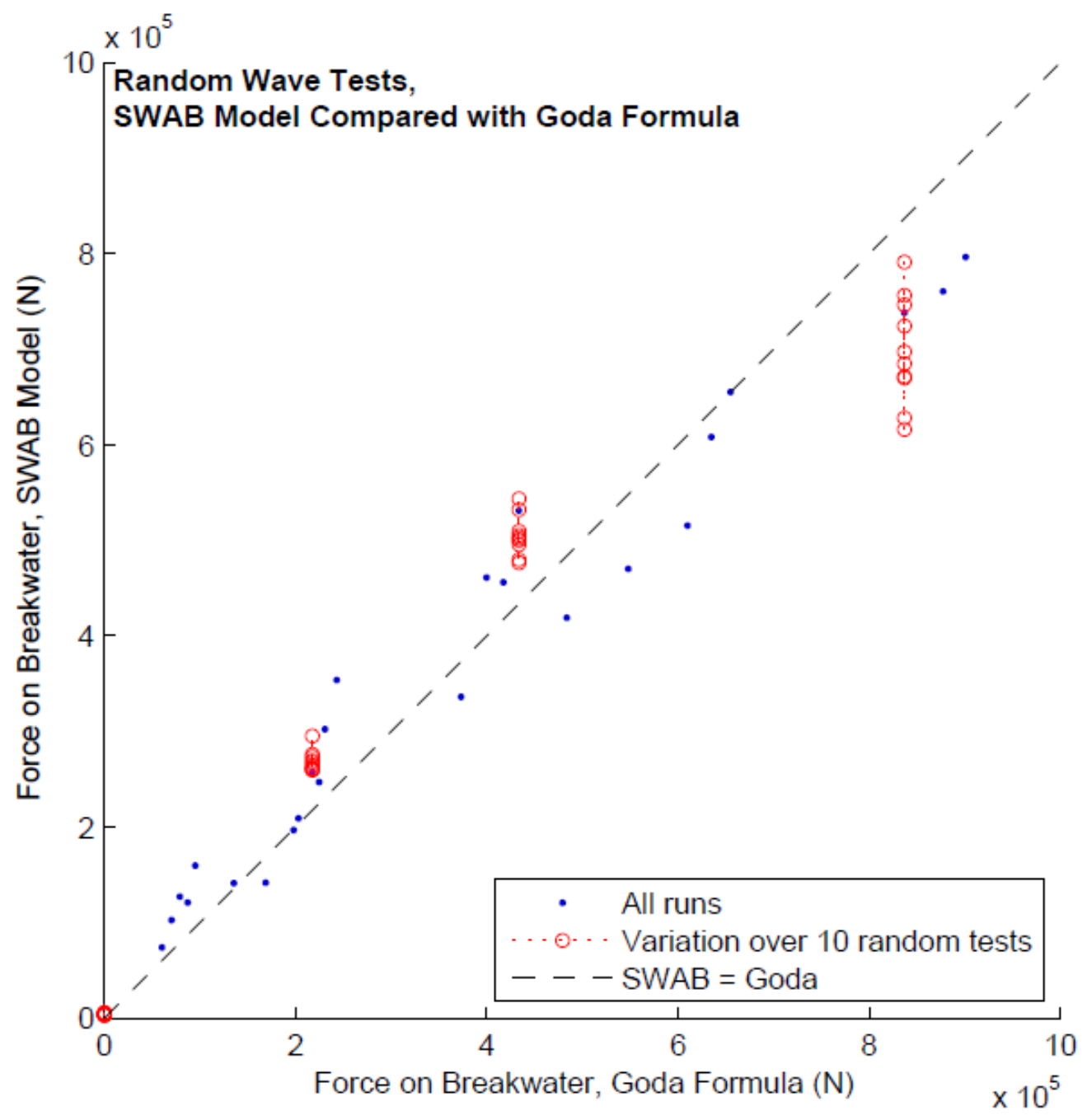

Figure 2. Force imposed on a vertical breakwater: SWAB simulations compared with Goda's formulae. 

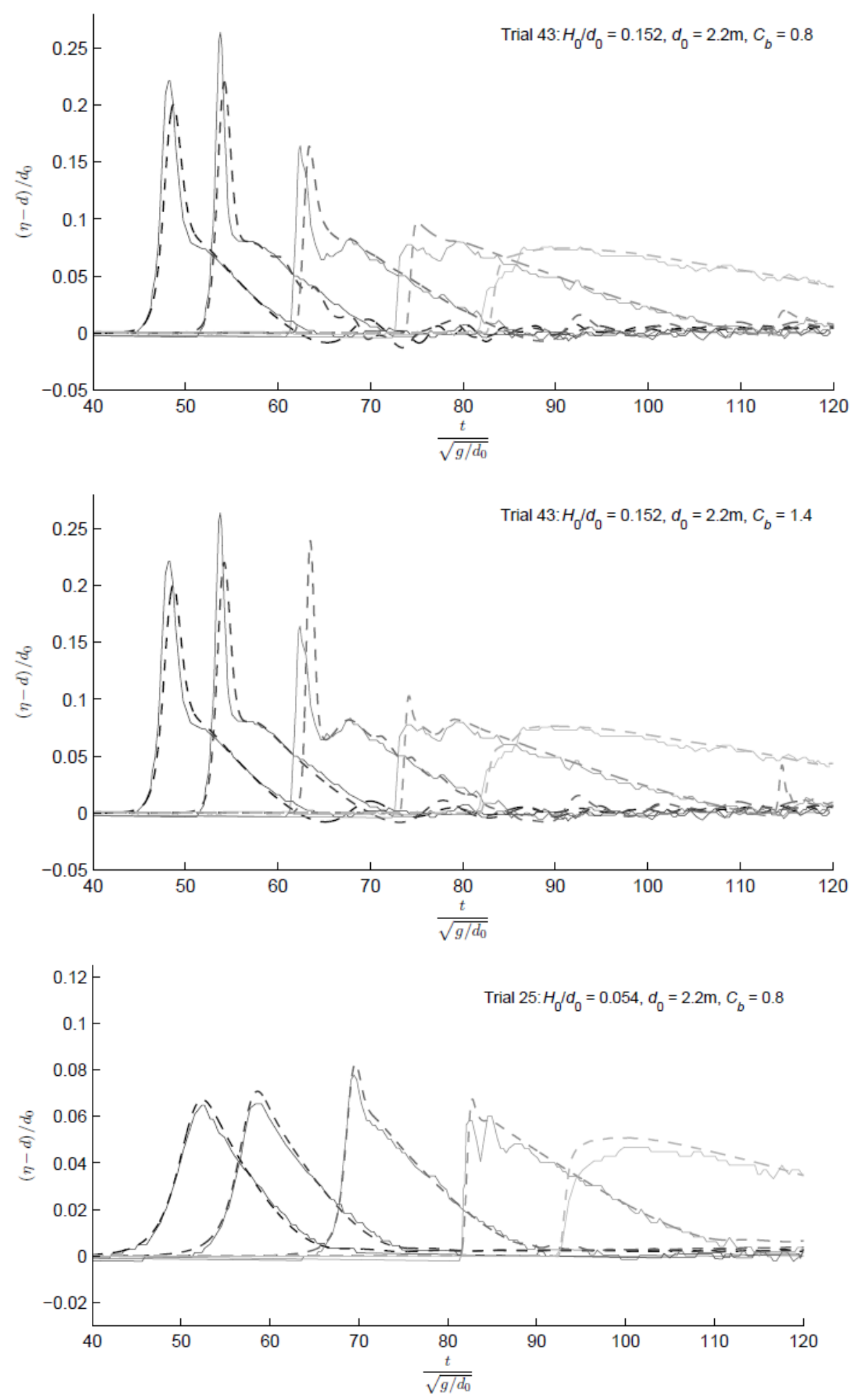

Figure 3. SWAB runs (dotted lines) of Hsiao et al. (2008) solitary wave tests (solid lines). Free surface level time series at (from left to right) $x=130 \mathrm{~m}, 140 \mathrm{~m}, 156 \mathrm{~m}, 172 \mathrm{~m}$ and $182 \mathrm{~m}$ from wave input location. SWAB breaking coefficient, $C_{b}=0.6$ in Fig. 3(a) (top), and $C_{b}=1.4$ in Fig. 3 (b) (middle). Time is measured from when wave crest passes first wave gauge ( $x=24 \mathrm{~m}$ ). 


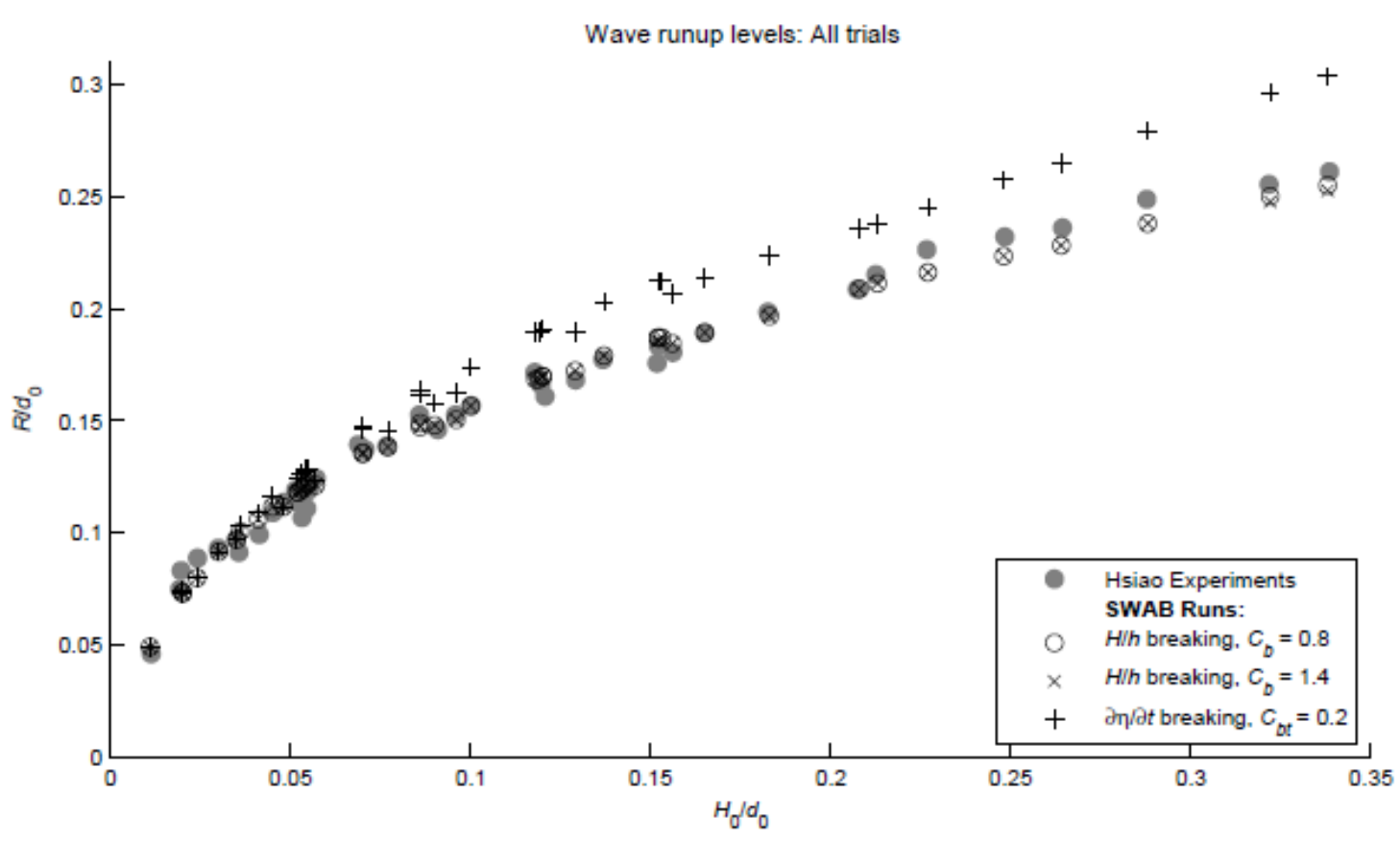

Figure 4. Wave runup levels from Hsiao et al. (2008) solitary wave tests, showing SWAB simulated values for different breaking criteria. Note: a cross $(x)$ within a circle (o) represent points where $C_{b}=0.6$ and $C_{b}=1.4$ give equal runup levels. 


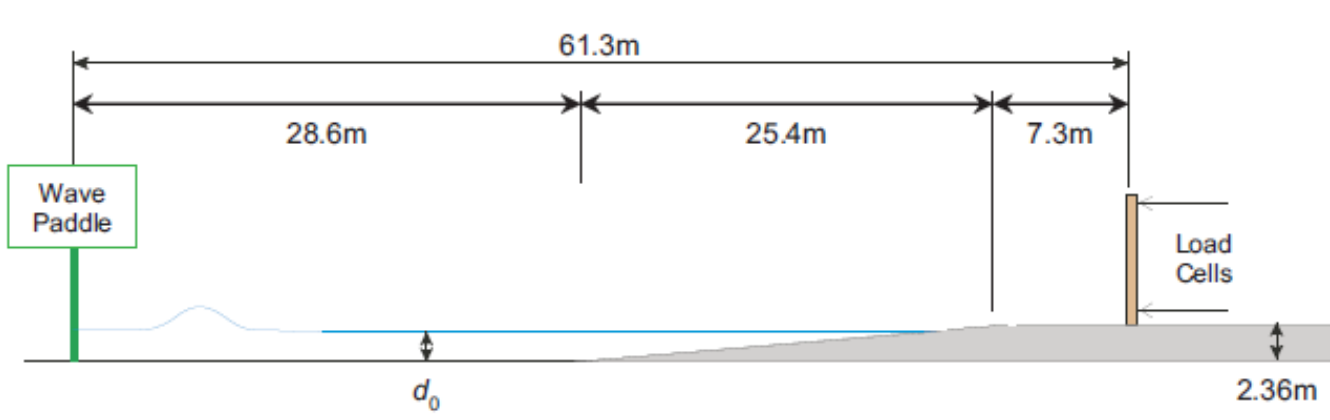

Figure 5. Linton et al. (2013) wave flume set-up. 


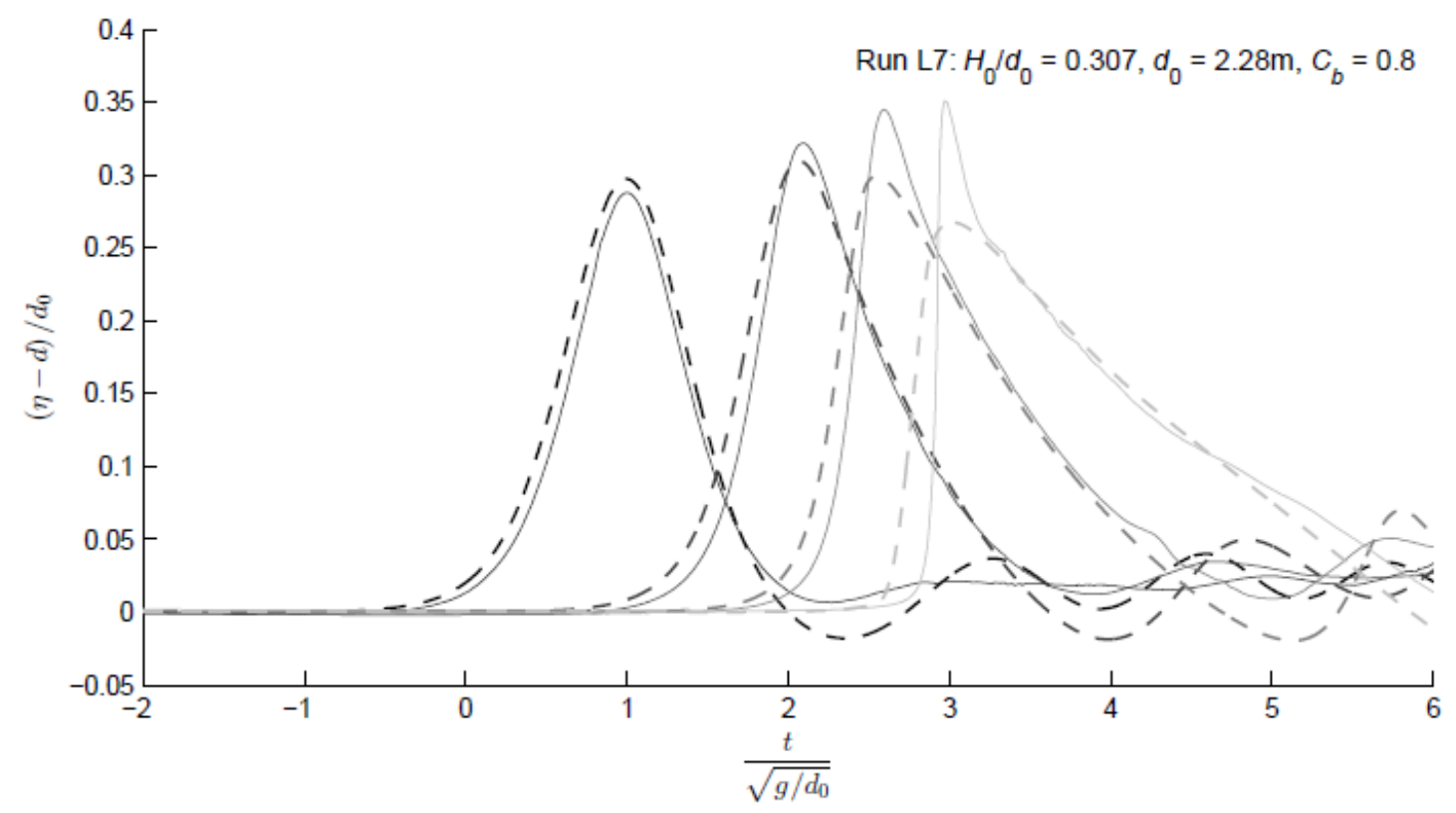

a)

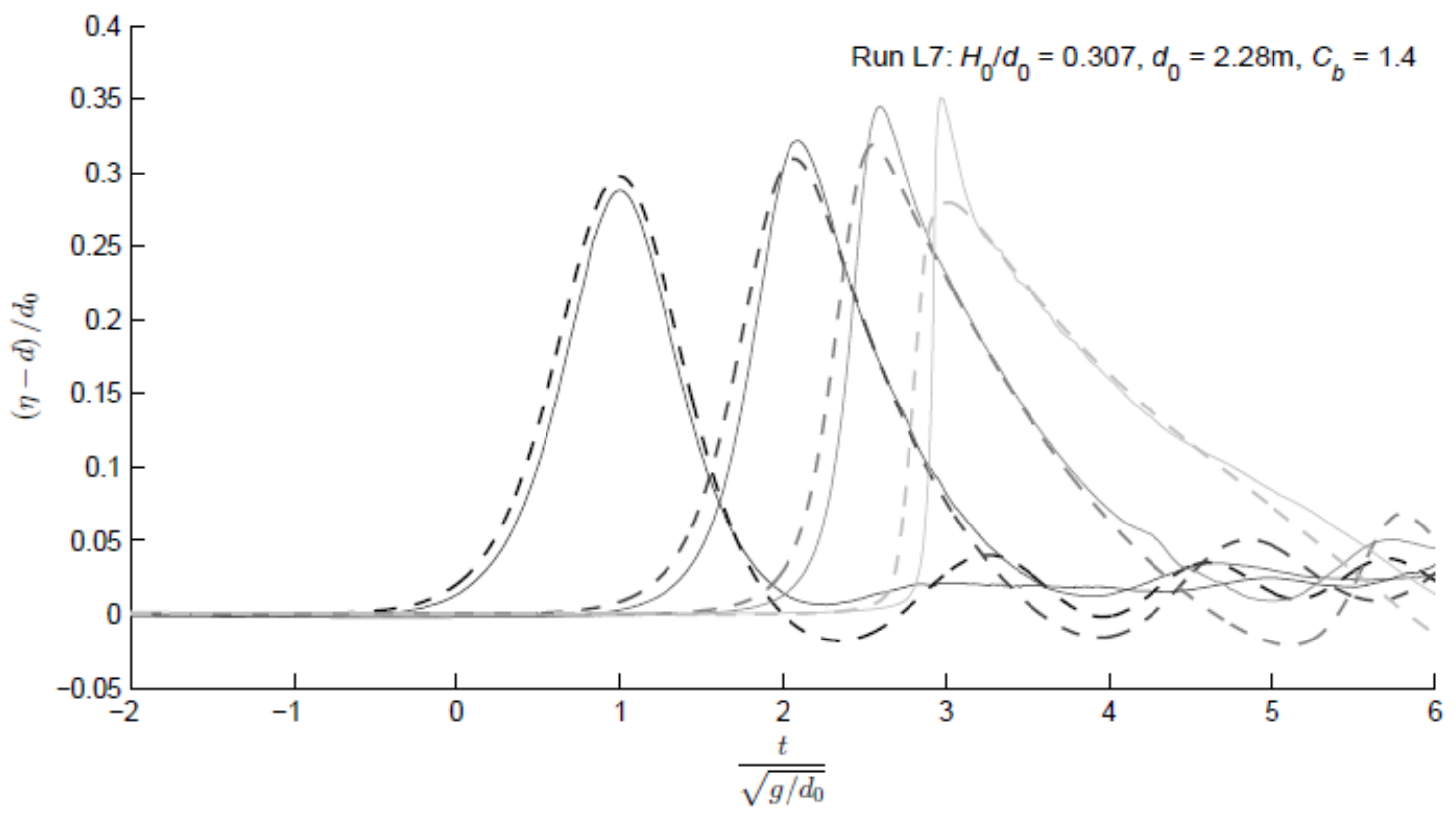

b)

Figure 6. Two SWAB runs (dotted lines) of Linton et al. (2013) solitary wave test L7 (solid lines), with breaking coefficient (equation 4 ) of 0.8 and 1.4 respectively. Free surface level time series at (from left to right) $x=28.6 \mathrm{~m}, 40.6 \mathrm{~m}, 46.1 \mathrm{~m}$ and $50.4 \mathrm{~m}$ from wave input location / wave paddle. Time is measured from when wave crest passes first wave gauge (17.6 $\mathrm{m}$ from paddle). 


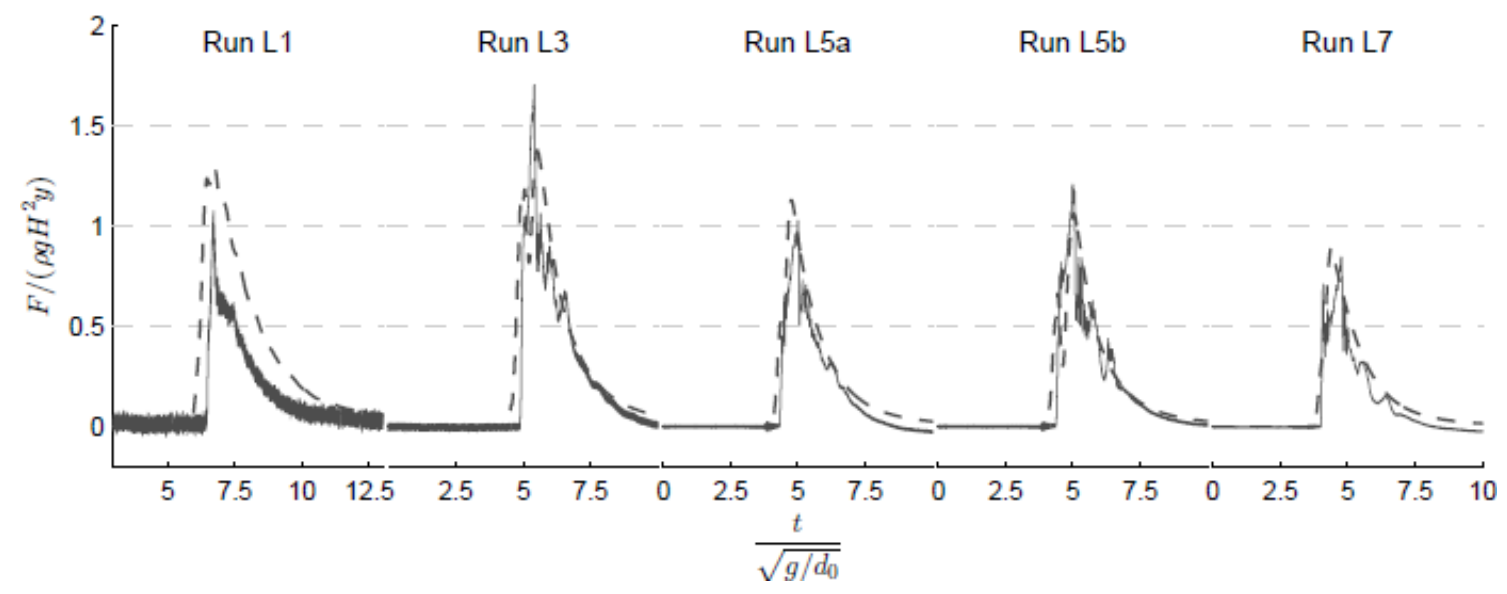

Figure 7. SWAB simulations (dotted lines) of forces imposed on a vertical wall (solid lines) recorded by Linton et al. (2013) Time is measured from when wave crest passes first wave gauge ( $17.6 \mathrm{~m}$ from paddle). SWAB model breaking coefficient $C_{b}=0.8$ for all cases.

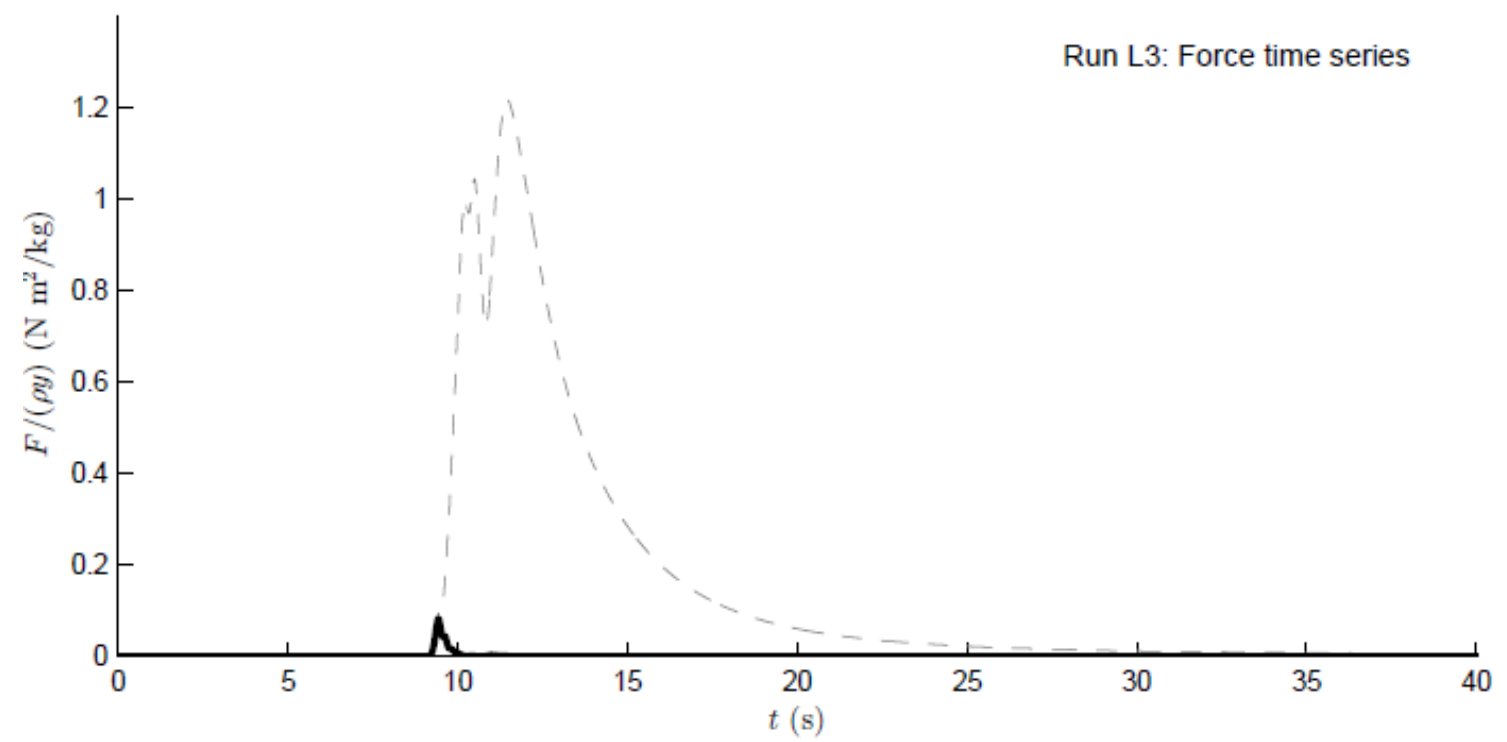

Figure 8. SWAB-simulated time series of total force imposed on wall for run $L 3$ (dashed line), showing contribution from reverse momentum term (solid line). 


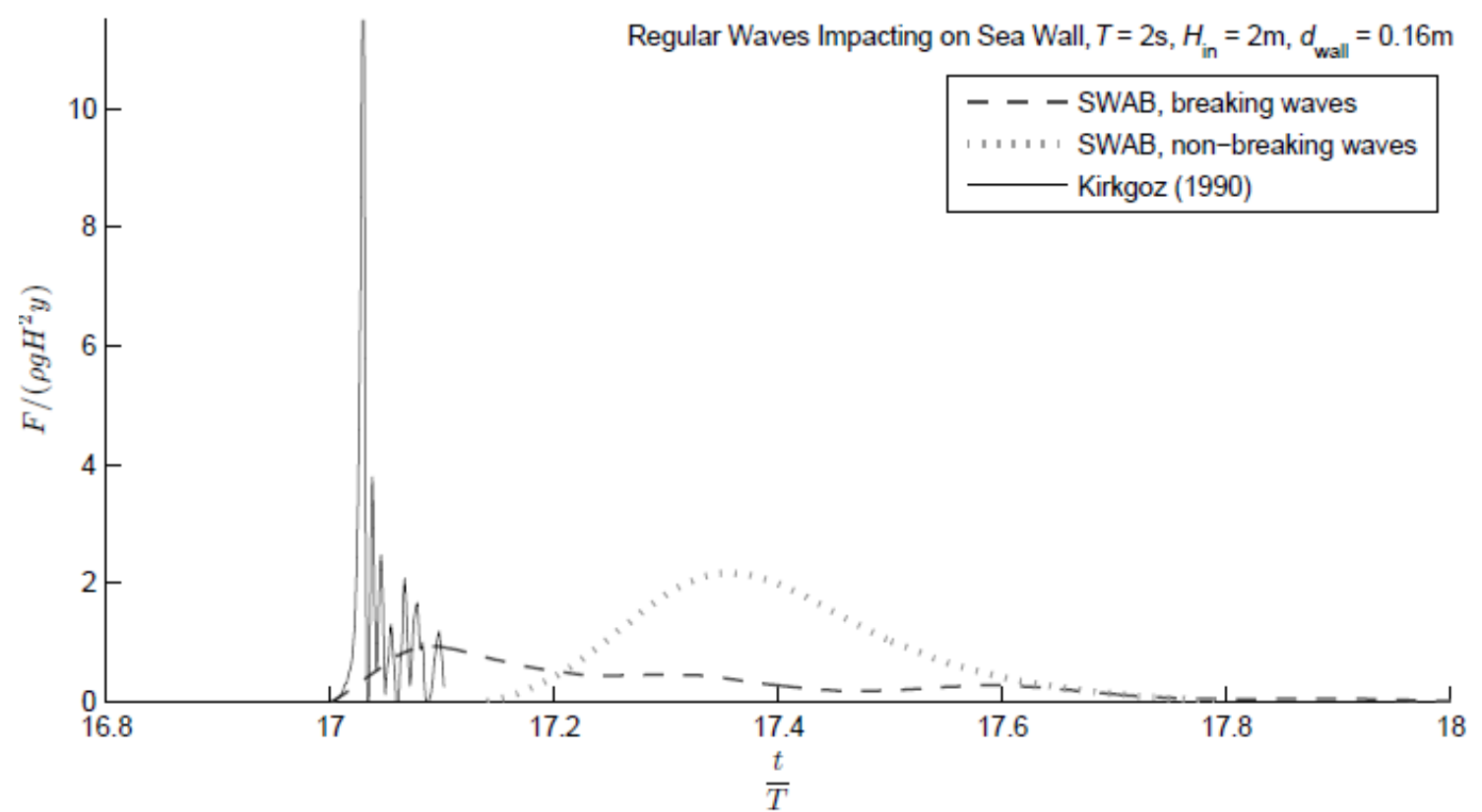

Figure 9. SWAB simulations of impulsive wave loading, compared with regular wave experiments of Kirkgoz (1990).

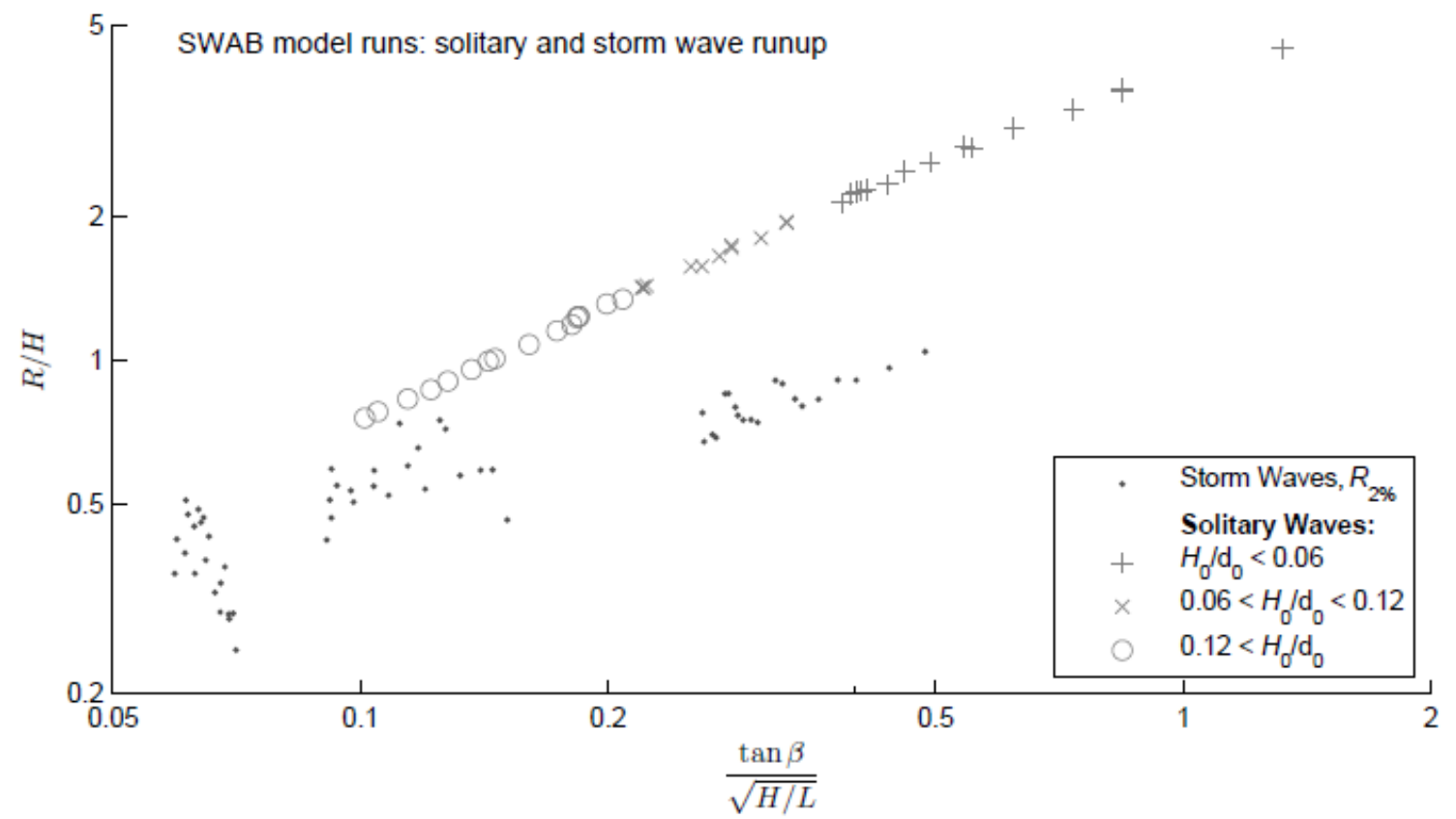

Figure 10. Wave runup levels (log scale) for storm and solitary waves as a function of surf similarity parameter (log scale). 

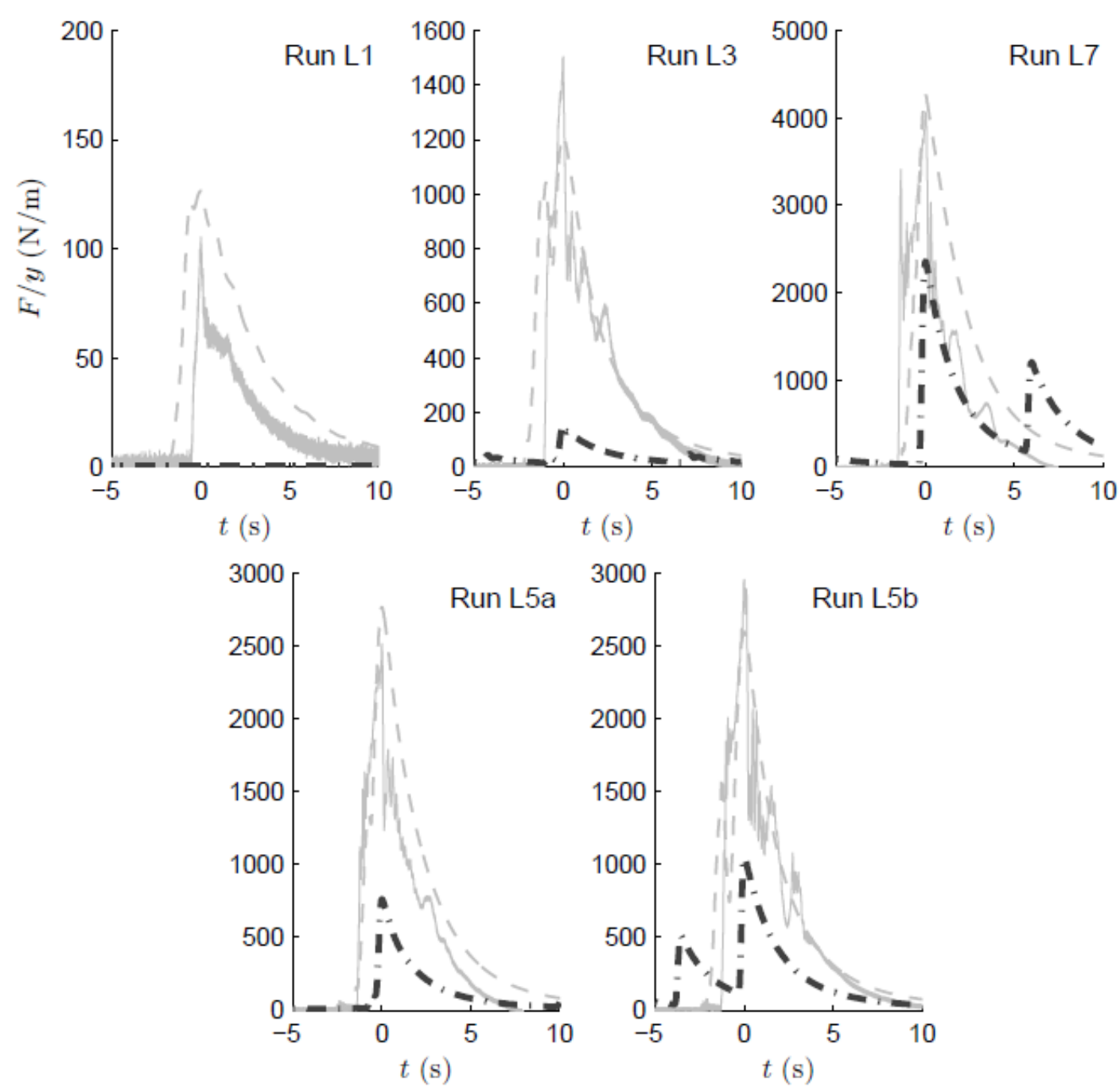

Expt data

- - - SWAB, solitary wave

! $=$ ! I SWAB, with max. random wave force

Figure 11. Time series of force on vertical wall from Linton et al. (2013) tests, showing maxima from SWAB runs of 200 random waves alongside experimental and numerical solitary wave data (time $t=0$ corresponds to time of maximum force). 